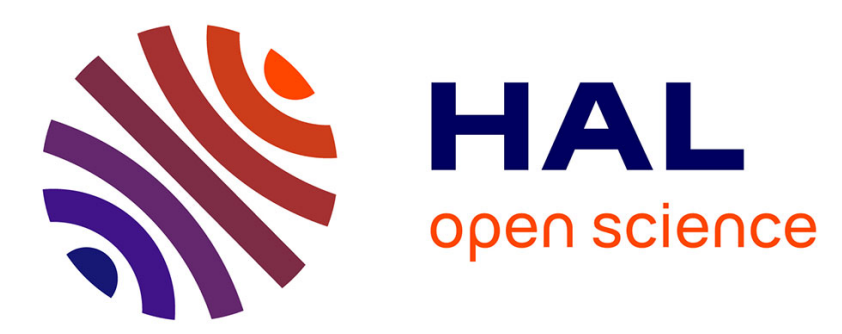

\title{
Does competition stress decrease allelopathic potential?
}

Annabelle Rivoal, Catherine Fernandez, Stephane Greff, Nicolas Montès,

\author{
Bruno Vila
}

\section{To cite this version:}

Annabelle Rivoal, Catherine Fernandez, Stephane Greff, Nicolas Montès, Bruno Vila. Does competition stress decrease allelopathic potential?. Biochemical Systematics and Ecology, 2011, 39 (4-6), pp.401-407. 10.1016/j.bse.2011.05.017 . hal-01764833

\section{HAL Id: hal-01764833 \\ https://hal-amu.archives-ouvertes.fr/hal-01764833}

Submitted on 12 Apr 2018

HAL is a multi-disciplinary open access archive for the deposit and dissemination of scientific research documents, whether they are published or not. The documents may come from teaching and research institutions in France or abroad, or from public or private research centers.
L'archive ouverte pluridisciplinaire HAL, est destinée au dépôt et à la diffusion de documents scientifiques de niveau recherche, publiés ou non, émanant des établissements d'enseignement et de recherche français ou étrangers, des laboratoires publics ou privés. 


\title{
Does competition stress decrease allelopathic potential?
}

\author{
Annabelle Rivoal, Catherine Fernandez, Stéphane Greff, Nicolas Montes, Bruno Vila* \\ Institut Méditerranéen d'Ecologie et de Paléoécologie, Case 4, Aix-Marseille Université, Centre Saint-Charles, 3 Place Victor Hugo, 13331 Marseille cedex 03, France
}

\section{Keywords:}

Pinus halepensis

Competition

Stress

Allelopathy

Phenolics

Biomass

Allocation

\begin{abstract}
A B S T R A C T
In natural communities, plants compete in different ways, among them chemical interactions in the form of allelopathy. Whereas the effects of abiotic stresses (temperature, light, nutrients, etc.) on the production of allelochemicals are well known, only few studies deal with the impact of the stress induced by competition. When they do so, these studies are done under experimental conditions. The aim of this study is to evaluate the effect of intra-specific competition on the production of allelochemicals and biomass of Pinus halepensis Mill. in a natural forest using three levels of density. Phenolics and aliphatic acids were extracted from pine needles, analysed and quantified by GC-MS. Trunks, branches, needles and necromass were measured. We observed an increase in allelochemical content at low or medium level of competition and a decrease at high competition level. Moreover trees in competition allocate proportionally more biomass to the trunk and less to foliage and branches. This study provides evidence of substantial changes in allocation between the primary and the secondary metabolism.
\end{abstract}

\section{Introduction}

In natural communities, plants compete in complex ways as they struggle for the same resources. These interactions can be classified as direct or indirect competition. For direct competition, many plants have recourse to chemical interactions, such as allelopathy (Lambers et al., 1998; Inderjit and Duke, 2003). This passive interference by releasing allelochemicals into the environment negatively impacts surrounding plants, thus giving the producer a competitive advantage (Rice, 1984; Reigosa et al., 2002) that could enable it to acquire a higher proportion of available resources.

Allelopathy is a phenomenon strongly related to the interaction of producer plants with their environment. Abiotic and biotic factors may influence the production of allelochemicals and could alter the impact of allelopathy under natural conditions as well as in agro-systems (Einhellig, 1996; Gawronska and Golisz, 2006). Generally, donor plants exposed to stresses respond by the production of higher concentrations (constitutive defence) and/or the synthesis of new molecules (induced defence) often implicated as allelopathics (Reigosa et al., 1999; Blanco, 2007). Most studies have focused on the relationship between environmental variation, plant chemical response and the ecological function of plant allelochemicals (Kong et al., 2002). The effects of some abiotic stresses on the production of allelochemicals, such as high temperature, modified light quality, soil characteristics $(\mathrm{pH}$, structure and nutrient status, texture, presence of contaminants), altitude and latitude, are already known (Rice, 1984; Einhellig, 1996; Blanco, 2007). Biotic stresses such as pathogens, pests, parasites or herbivores can also stimulate allelochemical production and have been evidenced in

\footnotetext{
* Corresponding author. Tel.: +33413551229.

E-mail address: bruno.vila@univ-provence.fr (B. Vila).
} 
numerous studies (Kiraly and Farkas, 1962; Bruce and Pickett, 2007). However, the effects of plant-plant interactions are less well known. Only a few studies deal with the stress induced by competition and these are generally based on experimentation under controlled conditions (green-house). Gawronska and Golisz (2006) report that the allelopathic potential of plants competing for limited resources such as nutrients, light, etc., will most likely be enhanced due to the increased biosynthesis of allelochemicals (Einhellig, 1996). For example, under controlled conditions, Kong et al. (2002) have shown that the total amount of volatiles synthesised by Ageratum conyzoides L. increased significantly when it was grown in competition with Bidens pilosa L. Similarly, under experimental conditions, (Ormeño et al., 2007a,b) offered evidence that plant competition alters terpene emissions and content of Mediterranean shrubs. Under natural conditions, the effect of plant competition on allelochemical production has been less widely studied, in particular for woody species, even if the importance of chemical interactions among plants in forest development or dynamics has already been noted (Mallik, 2003; Fernandez et al., 2008).

In the Mediterranean basin, Pinus halepensis Mill. is one of the major tree species in terms of the area it covers, and of ecological and economic values (Quézel, 2000). It is rich in secondary metabolites (Pasqua et al., 2002; Macchioni et al., 2003; Maestre et al., 2003; Robles et al., 2003) that could play an important role in secondary succession because of its allelopathic potential (Gallet and Pellissier, 1997; Fernandez et al., 2006, 2008, 2009) and its autotoxicity when regenerating (Fernandez et al., 2008).

In order to evaluate the effect of intra-specific competition on the production of potential allelochemicals in natural environment, we studied the variation of phenolics and aliphatic acids of $P$. halepensis needles under a gradient of competition in a natural forest of young trees. Furthermore, we used tree biomass, a well known parameter in forestry, as a second indicator of competition impact on the tree.

\section{Material and methods}

\subsection{Study site}

The site is located on the southern slopes of the Massif du Luberon (Luberon mountain range, Provence, France, $43^{\circ} 45^{\prime} 24 \mathrm{~N}, 5^{\circ} 19^{\prime} 09 \mathrm{E}$ ) at an altitude of $217 \mathrm{~m}$. Climatic conditions are Mediterranean with annual precipitation of $666 \mathrm{~mm}$, mean annual temperature of $13.2^{\circ} \mathrm{C} \pm 8.13^{\circ} \mathrm{C}$ (Mean $\pm \mathrm{SD}$ ) and 2 to 3 dry months in summer (Météo-France data). The topography of the selected station is flat, characterized by a colluvium more than $50 \mathrm{~cm}$ deep with less than $10 \%$ of stones. Because allocation patterns change in response to environmental factors, bias resulting from site effects was avoided by using one station with homogenous environmental factors and variable tree density.

\subsection{Sampled trees and competition}

We chose plots with three contrasted levels of competition. Within each plot, 5 young trees (aged 10-25 years) were selected according to the homogeneity of competition index (Table 1). This index was calculated using Hegyi's distance-dependent index. Following Hegyi (1974), competition was described as the height of each sample tree in relation to the heights of and distances from neighbouring trees:

$$
C I_{x}=\sum_{i=1}^{n} \frac{D_{i}}{D_{x} \times \text { Dist }_{i x}}
$$

where $x$ is the subject tree and $i$ a neighbouring tree, $D$ is the basal diameter $(\mathrm{cm})$, Dist is the distance $(\mathrm{cm})$ between the subject tree and a neighbouring tree and $n$ is the number of neighbouring trees.

The first plot presented trees without competition or in limited competition, as they grow in isolation. This plot, indicated as $\mathrm{L}$, was characterized by a density of 0.2 tree $\mathrm{m}^{-2}$. The second plot presented trees in medium competition as they grow co-dominant in co-dominance. This plot, indicated as $\mathrm{M}$, was characterized by a density of 1.3 trees $\mathrm{m}^{-2}$. The third plot presented trees under high level of competition as they grew stunted through the canopy of dominant trees. This plot, indicated as $\mathrm{H}$, was characterized by a density of 2.0 trees $\mathrm{m}^{-2}$.

Table 1

Main characteristics of sampled trees: age, competition index, total height and basal diameter (Mean \pm SE) for the three classes ( $\mathrm{L}$ : Low tree density $=0.2$ tree $\mathrm{m}^{-2}$; M: Medium tree density $=1.3$ trees $\mathrm{m}^{-2}$ and $\mathrm{H}$ : High tree density $=2.0$ trees $\mathrm{m}^{-2}$ ).

\begin{tabular}{lllll}
\hline & Age (years) & Competition Index & Height $(\mathrm{m})$ & Basal diameter $(\mathrm{cm})$ \\
\hline $\mathrm{L}$ & $12.4 \pm 0.51$ & $0.012 \pm 0.007$ & $4.49 \pm 0.28$ & $10.18 \pm 0.92$ \\
$\mathrm{M}$ & $24.4 \pm 0.40$ & $0.138 \pm 0.021$ & $7.452 \pm 0.19$ & $6.38 \pm 0.77$ \\
$\mathrm{H}$ & $20.8 \pm 0.73$ & $0.43 \pm 0.007$ & $3.308 \pm 0.14$ & $1.96 \pm 0.10$ \\
\hline
\end{tabular}




\subsection{Chemical analyses}

Sampling was done under similar climatic conditions before the beginning of the growing season (March-April). For each of the 15 trees, $250 \mathrm{~g}$ of needles were collected over the whole crown (at the bottom, the middle and the top of the crown and in all directions) and were lyophilized and ground. Then aqueous solution of each sample was prepared at $80 \mathrm{~g} \mathrm{l}^{-1}$. Chemical analysis, adapted from Fiamegos et al. (2004), consisted of extraction/methylation of phenolics and aliphatic acids from these solutions into an organic layer (dichloromethane) using Phase Transfer Catalysts (PTC), followed by GC-MS analysis (Fernandez et al., 2006, 2009). The process was carried out in 35 ml-Pyrex ${ }^{\circledR}$ tubes (Bibby Sterilin Ltd) equipped with PTFE screw caps: to $10 \mathrm{ml}$ sample aqueous solution was added a stirring bar, $500 \mu \mathrm{l}$ buffer solution KH2PO4 (1 M, pH 8.0), $50 \mathrm{mg}$ TBMP (tri-n-butylmethylphosphonium polymer bound $-1.4 \mathrm{mmol} \mathrm{Cl}^{-} / \mathrm{g}$ resin), $100 \mu \mathrm{l} \mathrm{THAB}$ (tetrahexylammonium bromure) $0.1 \mathrm{M}$ in dichloromethane, $50 \mu \mathrm{l}$ internal standard $(100 \mu \mathrm{g} / \mathrm{ml}$ of 3-chloroanisole in dichloromethane), $850 \mu \mathrm{l}$ dichloromethane and $100 \mu \mathrm{l}$ methyle iodure. Tubes were hermetically sealed, and heated to $80^{\circ} \mathrm{C}$ during $1 \mathrm{~h}$ to allow the methylation of compounds. After cooling, solutions were saturated with $\mathrm{NaCl}$ and shaken vigorously. After phase separation, the organic layer was sampled, filtered onto $0.45 \mu \mathrm{m}$ filter syringe, and analysed by GC-MS. Analyses were performed using a Hewlett-Packard GC6890 (coupled to a HP 5973N Mass Selective Detector) equipped with a HP5MS capillary column (30 $\mathrm{m} \times 0.25 \mathrm{~mm} \times 0.25 \mu \mathrm{m}-\mathrm{J} \& \mathrm{~W}$ Scientific). Sample volumes were injected in a splitless mode for $1 \mathrm{~min}$ with an ALS 7683 Automatic Injector. Purge flow was set to $50 \mathrm{ml} / \mathrm{min}$. Helium (99.995\%) was used as carrier gas. A constant flow of $1 \mathrm{ml} / \mathrm{min}$ was set throughout the run. Oven temperature initially set at $50{ }^{\circ} \mathrm{C}$ was increased to $220{ }^{\circ} \mathrm{C}$ at a rate of $5 \circ / \mathrm{min}$ where it remained for $6 \mathrm{~min}$. Injector temperature and MSD transfer line heater was held to 250 and $280^{\circ} \mathrm{C}$, respectively. The mass spectrometer parameters for EI mode were: ion source, $230{ }^{\circ} \mathrm{C}$; MS quadrupole, $150{ }^{\circ} \mathrm{C}$; electron energy, $70 \mathrm{eV}$; Electron Multiplier Energy, 1100-1200 V; data were acquired in "Selected Ion Monitoring" (SIM, 3 qualifiers and 1 quantifier) mode. Appropriate dilutions of stock solutions of standards (Sigma-Aldrich ${ }^{\circledR}$ ) were made to prepare calibration curves (constructed by taking the ratio of external variable standard to internal constant standard). Because of the methylation technique used, the quantified derivatives of sample solutions may include several allelochemicals. A detailed description of the method can be found in Fiamegos et al. (2004) and Fernandez et al. (2006, 2009). 14 allelochemical compounds were selected, on the basis of their ability to be methylated under these conditions (Fiamegos et al., 2004) and on their occurrence (qualitative analysis) in P. halepensis (Fernandez et al., 2006, 2009).

\subsection{Biomass analyses}

The 15 trees ( 5 by competition level) were cut down. Fresh trunks, branches, needles and necromass were weighed separately in the field. Sub-samples of trunk, branches and needles were taken to the laboratory and oven dried at $70^{\circ} \mathrm{C}$ until constant weight to convert fresh mass into dry mass. The total biomass and the relative biomasses of trunk, branches and needles were calculated for comparisons (biomass considered/total biomass).

\subsection{Soil sampling and nitrogen analyses}

Soil samples were taken a few $\mathrm{cm}$ under litter layer, avoiding litter fragments. Five soil samples were collected randomly on each plot. The soil samples were oven dried at $60^{\circ} \mathrm{C}$ for $48 \mathrm{~h}$, sieved and ground in a ball mill. For each sample, 3 sub-samples (replicates analysis) of soil N content were analyzed with a Flash EA 1112 Elemental Analyzer (Thermo Finnigan, Milan, Italy).

\subsection{Statistical analysis}

Differences in tree biomass and in each compound concentration according to competition classes (L, M, H) were tested using one-way ANOVA test followed by post-hoc Tukey test (Zar, 1984). In order to check ANOVA assumptions, normality of the distributions and variance homogeneity were tested by Shapiro-Wilks' and Bartlett's tests, respectively. Dependency of compound concentration on competition index was analyzed using regression analyses. Soil Nitrogen data were tested using Kruskall-Wallis test, according to competition classes. Statgraphics ${ }^{\circledR}$ (version 4.1) was used for these statistical analyses.

\section{Results}

\subsection{Chemical analyses of needles}

All of the 14 allelochemicals studied were observed in the extracts of needles of P. halepensis growing at different levels of competition. On the basis of their concentration four groups can be constituted: (1) succinic acid and palmitic acid are the most abundant compounds, (2) stearic acid, protocatechuic acid, pyrogallol, p-coumaric acid and gallic acid are observed in intermediate concentrations, (3) caffeic acid, 4-hydroxybenzoic acid and acetovanillone are present at low concentrations and (4) azelaic acid, catechol, acetosyringone, and sinapic acid are the least abundant compounds (Fig. 1). A significant effect of competition on chemical content was observed. In high density (H class), trees presented a lower total concentration of compounds than trees of the other classes ( $\mathrm{L}$ and $\mathrm{M}$ classes; ANOVA, $F=10.70$ and $P<0.01$ ). Concentrations of 5 allelochemicals of the 14 studied varied significantly with competition. Trees of classes L and $\mathrm{M}$ had significantly higher 
concentrations of succinic acid than class $\mathrm{H}$ trees (ANOVA, $F=55.75, P<0.001$ ). Class $\mathrm{M}$ trees had significantly higher concentrations of 4-hydroxybenzoic acid and protocatechuic acid than class $\mathrm{H}$ trees $(F=6.78, P<0.05$ and $F=7.11, P<0.01$ respectively), class $\mathrm{L}$ trees presented intermediate concentrations. Class $\mathrm{M}$ trees had significantly higher concentrations of azelaic acid and acetovanillone than trees of the other classes $(F=11.02, P<0.01$ and $F=13.84, P<0.001$ respectively). Moreover, a negative correlation of the competition index with several compounds was observed: succinic acid, 4-hydroxybenzoic acid and gallic acid decrease significantly when the competition index increases $(r=-0.91, F=63.67$, $P<0.001 ; r=-0.54 ; F=5.26, P<0.039 ; r=-0.52, F=4.87, P<0.046$ respectively, Table 2 ). Consequently, a significant negative linear correlation was apparent between the total content of the three compounds and the competition indexes of trees $(r=-0.60 ; F=7.39 ; P<0.018$; Table 2).
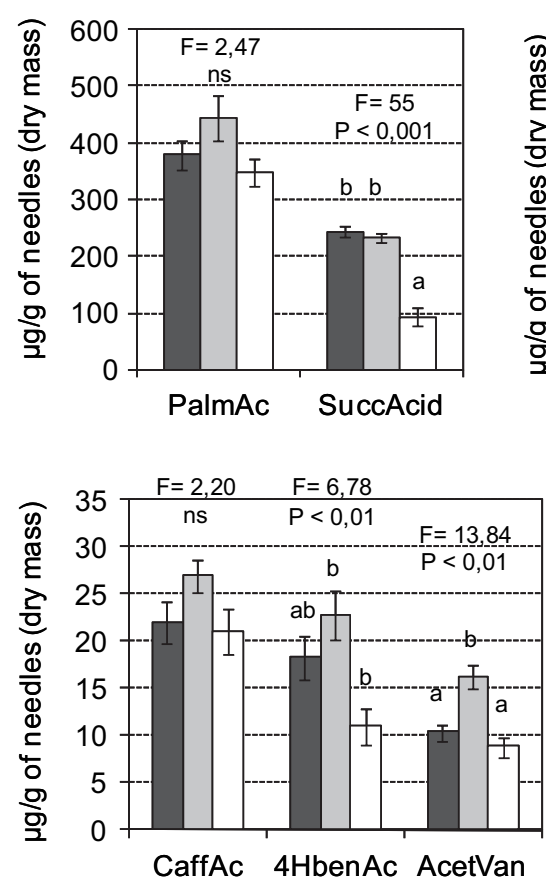
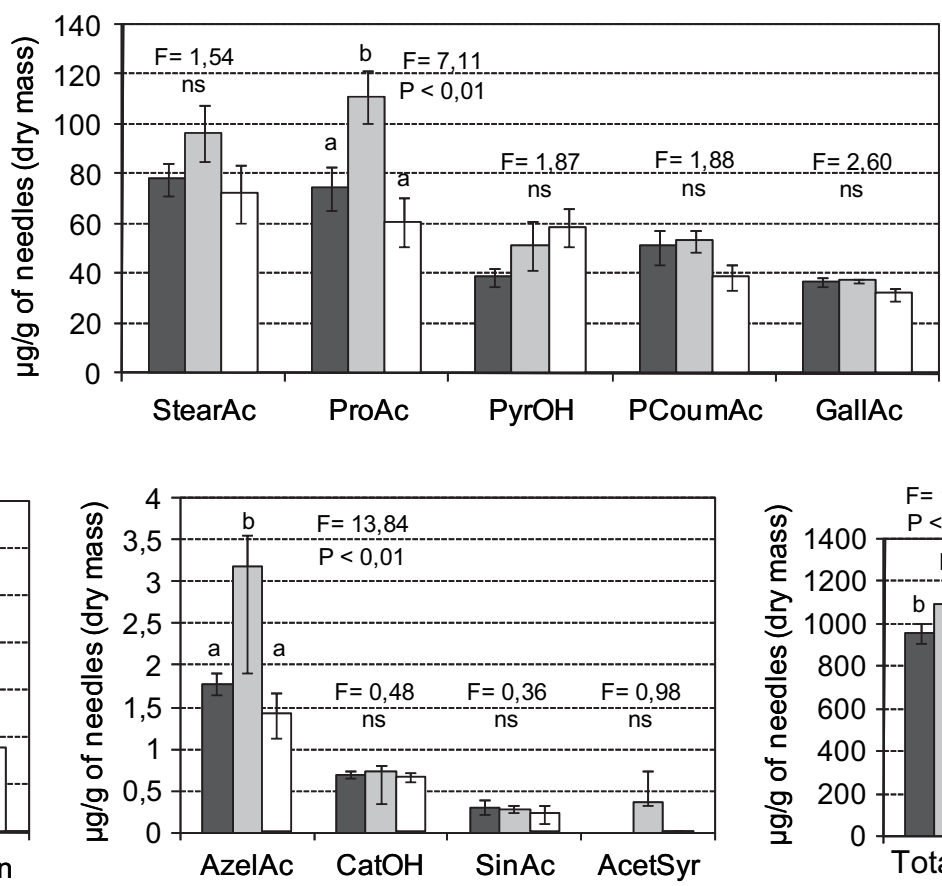

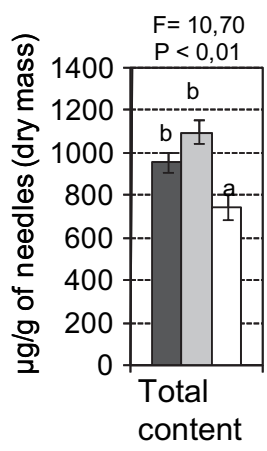

Fig. 1. Concentrations (Mean \pm SE; $n=5$ for competition level) of the 14 allelochemicals studied and the total concentration (Total content) observed in the extracts of needles of $P$. halepensis growing at different levels of competition (Black: Low tree density $=0.2$ tree $\mathrm{m}^{-2}$; Grey: Medium tree density $=1.3$ trees $\mathrm{m}^{-2}$ and White: High tree density $=2.0$ trees $\mathrm{m}^{-2}$ ). PalmAc $=$ palmitic acid, SuccAcid = succinic acid; StearAc $=$ stearic acid; ProAc $=$ protocatechuic acid; PyrOH = pyrogallol; PCoumAc = p-coumaric acid; GallAc = gallic acid CaffAc = caffeic acid 4HbenAc = 4-hydroxybenzoic acid; AcetVan = acetovanillone; AzelAc = azelaic acid $\mathrm{CatOH}=$ catechol; $\operatorname{SinAc}=$ sinapic acid; AcetSyr = acetosyringone. Letters within a sub-graph show significant differences as determined by Tukey's test: values which did not differ from the threshold by $0.05 \%$ are indicated with the same letter; ns if non-significant.

Table 2

Correlation $(r)$ and linear regression between competition index (CI) and phenolic compounds $(n=15)$. Results of the analyses of variance performed on each linear model are also presented $(F, P)$.

\begin{tabular}{|c|c|c|c|c|c|c|}
\hline & Slope & Intercept & $F$ & $P$ & Equation & $r$ \\
\hline Succinic Acid & -372.43 & 261.82 & 63.67 & 0.001 & SuccAcid $=261.826-372.433 * \mathrm{Cl}$ & -0.91128 \\
\hline 4-hydroxybenzonic acid & -20.28 & 21.22 & 5.26 & 0.039 & 4 HbenAc $=21.2292-20.2804 * \mathrm{Cl}$ & -0.53675 \\
\hline Gallic Acid & -12.71 & 37.65 & 4.87 & 0.046 & GallAc $=37.6536-12.7198 * \mathrm{Cl}$ & -0.52203 \\
\hline Total compounds & -612.65 & 1050.35 & 7.39 & 0.018 & Tot concent. $=1050.35-612.652 * \mathrm{Cl}$ & -0.60195 \\
\hline
\end{tabular}

\subsection{Biomass analyses}

Trees of class $\mathrm{L}$ had higher total biomass than trees of classes $\mathrm{M}$ and $\mathrm{H}$ (Fig. 2, ANOVA, $F=15.56, P<0.001$ ). Proportion of branches and needles were significantly higher for class $L$ than for others classes (ANOVA, respectively, $F=75.22, P<0.001$ and $F=43.20, P<0.001$ ). Proportions of trunk and necromass were significantly lower for class $\mathrm{L}$ than for the two other classes (respectively, $F=132.41, P<0.001$ and $F=14.22, P<0.001$ ). 

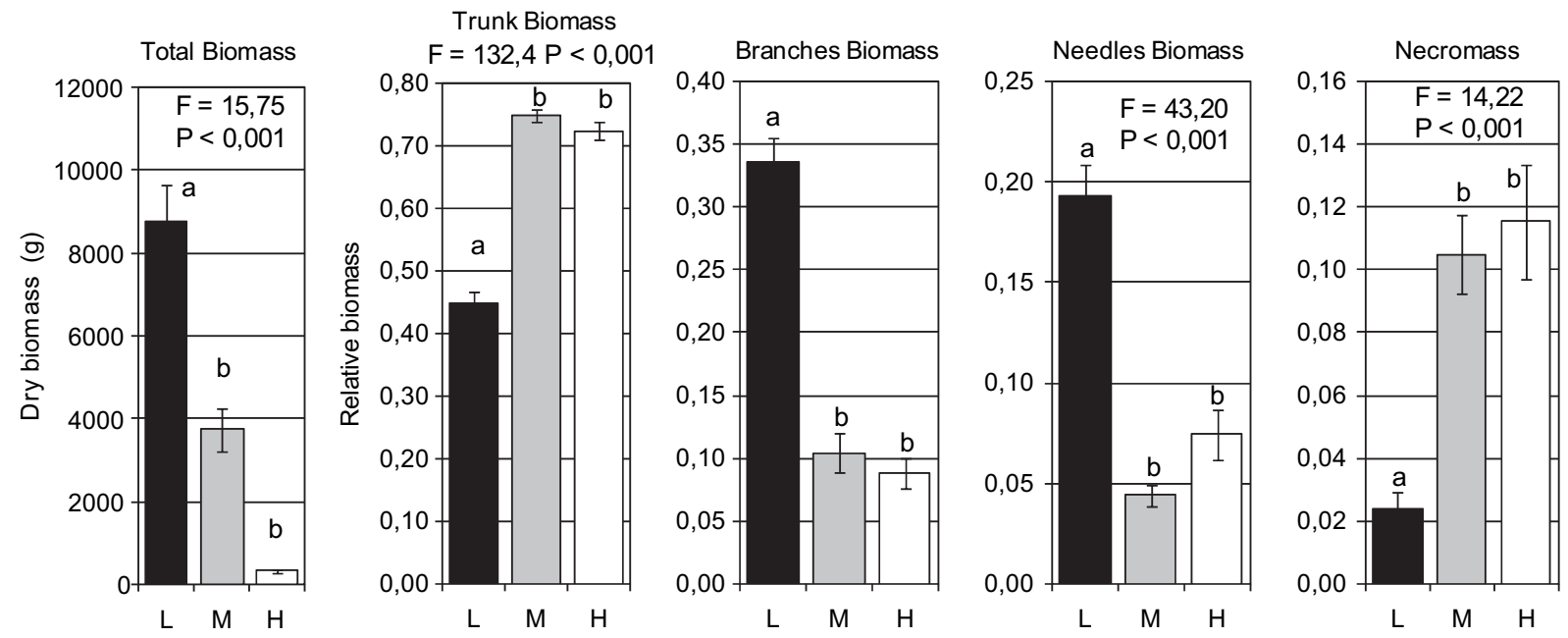

Fig. 2. Total biomass and relative biomass (biomass considered/total biomass) of trunk, branches, needles and necromass (Mean \pm SE $n=5$ for competition level)

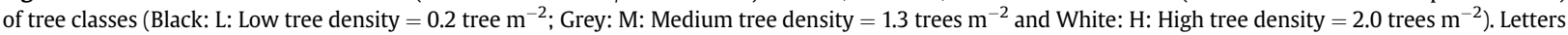
within a sub-graph show significant differences as determined by Tukey's test: values which did not differ from the threshold by $0.05 \%$ are indicated with the same letter; ns if non-significant.

\subsection{Nitrogen analyses of soil}

Values of mineral soil total nitrogen (Mean \pm SE) observed in the different plots were $0.063 \pm 0.003 \% ; 0.085 \pm 0.005 \%$ and $0.092 \pm 0.009 \%$ of dry mass for $\mathrm{H}, \mathrm{M}$ and L classes respectively. Mineral soil total nitrogen varied significantly between the different levels of competition (Kruskall-Wallis test, $W=7.02 ; P<0.05$ ): in high density (H class), soil presented a lower nitrogen content than soils of the other classes (L and M classes; NSK post-Hoc test $P<0.05$ ).

\section{Discussion and conclusion}

In our study, allelochemical compounds and biomass varied significantly with competition. Trees under high competitive stress (class $\mathrm{H}$ ) showed a lower needle concentration of allelochemicals than trees that are less stressed (classes $\mathrm{L}$ and $\mathrm{M}$ ). Moreover, a negative correlation was observed between some compounds (e.g. succinic acid, the second most highly concentrated compound) with the competition indexes of trees. This reduction of defensive compounds under competition was also observed by Cipollini and Bergelson (2001), Ormeño et al. (2007b) and Stamp et al. (2004) respectively in Brassica, Rosmarinus and Lycopersicon under experimental conditions. As stated by these authors, the lower nutrient availability can explain the reduced concentration of allelochemicals in stressed plants. Indeed, under high competition stress, the plant had to favour height growth in order to receive enough light (or light of good quality), a phenomenon probably inducing modification in allocation between the primary and the secondary metabolism. This seems to be attested by our observations on biomass. Indeed, trees of class $\mathrm{H}$, under high competitive stress, allocated proportionately more biomass to the trunk and less to foliage and branches than trees of class L. As a consequence, biomasses of branches and needles were strongly reduced inducing a drastic decrease of the secondary metabolism closely linked to the foliar biomass. Moreover, the production of phenolics, particularly flavonoids, must be highly affected by the modification of the light quality (wavelength and photoperiod of radiations) and intensity (Koeppe et al., 1970; Reigosa et al., 1999). Trees under medium competitive stress (class M) showed a higher concentration of 4 compounds among the 14 identified and quantified even if these compounds were not the major ones. Our results confirm those obtained by (Ormeño et al., 2007a,b) who observed, for $P$. halepensis, under experimental conditions with intra-specific competition, an increase of terpenoid emission at low or medium competition level (when nutrients are available) and a decrease of terpenoid emission at high competition level (at low nutrient concentration). These results show that moderate competition can increase the concentration of some allelochemicals, as stated by An et al. (2003), by modifying the relative importance of the metabolic pathways in relation to each other, as observed by Donaldson et al. (2006).

Nonetheless, our results on the competition effect on allelochemical production and biomass fit for the most part with the Growth Differentiation Balance Hypothesis which states that secondary metabolite production, such as that of phenolic compounds, and growth are limited under low resource availability (Herms and Mattson, 1992). In addition, the GDBH predicts that intermediate levels of resource result in an increase of allelochemical production which would occur simultaneously with an increase in photosynthetic activity, whereas for high levels of resource, a decrease in allelochemical production and high photosynthetic efficiency may be expected, because carbon synthesized through photosynthesis would be allocated rather to growth than to differentiation (in part represented by phenolic production). In our study, (1) for high competition, characterized by the lower soil nutrient availability, growth and allelochemical content were low as expected by 
the GDBH theory; (2) for intermediate competition, we observed an increase of allelochemical content and growth as also expected; finally (3) for low competition, growth was enhanced, but allelochemical content did not decrease (Fig. 3). Our results seem to indicate that, with regard to the resource availability, the last two classes (medium and low) are not contrasted enough to fit the last part of the GDBH theory (Fig. 3).

\section{Growth-Differentiation Balance Hypothesis}

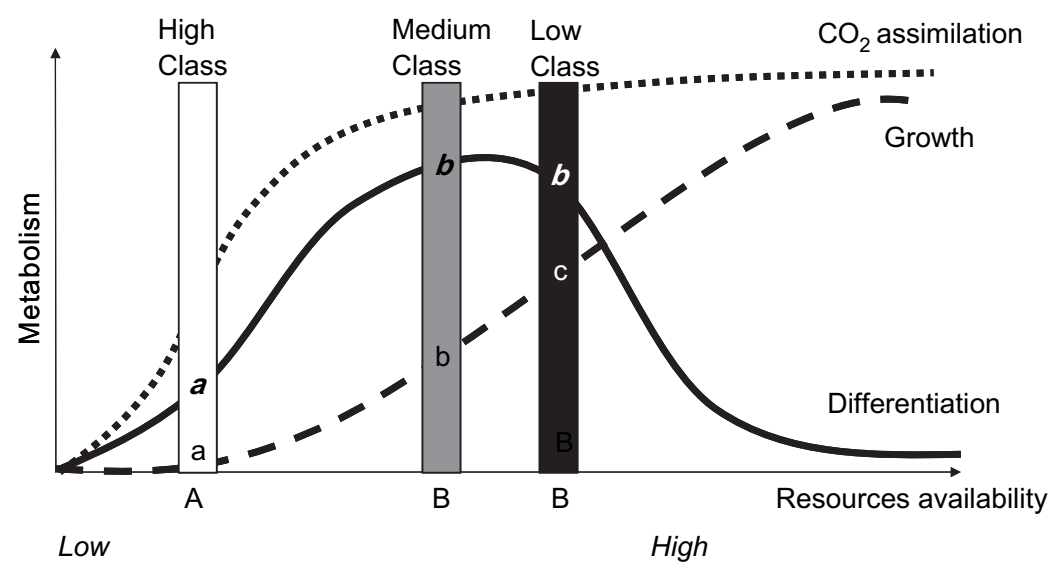

Fig. 3. Position of the three competition classes (Black: Low tree density $=0.2$ tree $\mathrm{m}^{-2}$; Grey: Medium tree density $=1.3$ trees $\mathrm{m}^{-2}$ and White: High tree density $=2.0$ trees $\mathrm{m}^{-2}$ ) in growth differentiation balance hypothesis scheme (from Herms and Mattson, 1992) and corresponding statistical results for resource availability (uppercase); differentiation (lowercase) and growth (lowercase italics and bold).

In conclusion, this study was undertaken in order to contribute to a better understanding of intra-specific competition, that alters the production of allelochemicals in natural forests of $P$. halepensis. It evidences changes in (1) allelochemical content: an increase at low or medium level of competition and a decrease at high competition level, and changes in (2) biomass repartition: competing trees allocate proportionately more biomass to the trunk and less to foliage and branches. This indicates substantial alterations in allocation between the primary and the secondary metabolism. In a broader perspective, it might be of interest to examine whether the patterns of production of allelochemicals from other Mediterranean tree species show the same response.

\section{Acknowledgments}

We would like to thank Sylvie Dupouyet, Françoise Blanc-Fleury and Caroline Lecareux for their assistance.

\section{References}

An, M., Liu, D.L., Johnson, I.R., Lovett, J.V., 2003. Mathematical modelling of allelopathy: II. The dynamics of allelochemicals from living plants in the environment. Ecol Model 161, 53-66.

Blanco, J.A., 2007. The representation of allelopathy in ecosystem-level forest models. Ecol Model 209, 65-77.

Bruce, T.J.A., Pickett, J.A., 2007. Plant defence signalling induced by biotic attacks. Curr Opin Plant Biol 10, 387-392.

Cipollini, D.F., Bergelson, J., 2001. Plant density and nutrient availability constrain constitutive and wound-induced expression of trypsin inhibitors in Brassica napus. J Chem Ecol 27, 593-610.

Donaldson, J.R., Kruger, E.L., Lindroth, R.L., 2006. Competition- and resource-mediated tradeoffs between growth and defensive chemistry in trembling aspen (Populus tremuloides). New Phytol 169, 561-570.

Einhellig. F.A., 1996. Interactions involving allelopathy in cropping systems. Agron J 88, 886-893.

Fernandez, C., Lelong, B., Vila, B., Mevy, J.-P., Robles, C., Greff, S., Dupouyet, S., Bousquet-Melou, A., 2006. Allelopathic potential of Pinus halepensis in secondary succession on abandon agricultural land. Chemoecology 16, 97-105.

Fernandez, C., Voiriot, S., Mevy, J.-P., Vila, B., Ormeño, E., Dupouyet, S., Bousquet-Melou, A., 2008. Regeneration failure of Pinus halepensis Mill.: the role of autotoxicity and some abiotic environmental parameters. For Ecol Manage 255, 2928-2936.

Fernandez, C., Monnier, Y., Mévy, J.-P., Baldy, V., Greff, S., Pasqualini, V., Ormeño, E., Bousquet-Mélou, A., 2009. Variations in allelochemical composition in leatchates of different organs and maturity stages of Pinus halepensis. J Chem Ecol 35, 970-979.

Fiamegos, Y.C., Nanos, C.G., Vervoort, J., Stalikas, C.D., 2004. Analytical procedure for the in-vial derivatization-extraction of phenolic acids and flavonoids in methanolic and aqueous plant extracts followed by gas chromatography with mass-selective detection. J Chromatogr 1041, 11-18.

Gallet, C., Pellissier, F., 1997. Phenolic compounds in natural solutions of a coniferous forest. J Chem Ecol 23, 2401-2412.

Gawronska, H., Golisz, A., 2006. Allelopathy and biotic stresses. In: Reigosa, M.J., Pedrol, N., Gonzales, L. (Eds.), Allelopathy: A Physiological Process with Ecological Implications, pp. 211-227.

Hegyi, F., 1974. A simulation model for managing jack pine stands. In: J, Fries (Ed.), Growth Models for Tree and Stand Simulation. Royal College of Forestry, Stockholm, pp. 74-90.

Herms, D.A., Mattson, W.J., 1992. The Dilemma of plants - to grow or Defend. Q Rev Biol 67, 283-335.

Inderjit, Duke, S.O., 2003. Ecophysiological aspects of allelopathy. Planta 217, 529-539. 
Kiraly, Z., Farkas, G.L., 1962. Relation between phenol metabolism and stem rust resistance in wheat. Phytopathology 52 (7), $657-664$.

Koeppe, D.E., Rohrbaugh, L.M., Rice, E.L., Wender, S.H., 1970. The effect of X-radiation on the concentration of scopolin and caffeoylquinic acids in tobacco. Radia Bot 10, 261-265.

Kong, C.H., Hu, F., Xu, X., 2002. Allelopathic potential and chemical constituents of volatiles from Ageratum conyzoides under stress J. Chem Ecol 28, 1173-1182.

Lambers, H., Chapin, I.F.S., Pons, T.L., 1998. Plant Physiological Ecology. Springer-Verlag, New York.

Macchioni, F., Cioni, P.L., Flamini, G., Morelli, I., Maccioni, S., Ansaldi, M., 2003. Chemical composition of essential oils from needles, branches and cones of Pinus pinea, P. halepensis, P. pinaster and P. nigra from central Italy. Flavour Fragance J 18, 139-143.

Maestre, F.T., Cortina, J., Bautista, S., Bellot, J., 2003. Does Pinus halepensis facilitate the establishment of shrubs in Mediterranean semi-arid afforestations? For Ecol Manage 176, 147-160.

Mallik, A.U., 2003. Conifer regeneration problems in boreal and temperate forests with ericaceous understory: role of disturbance, seedbed limitation, and keytsone species change. Crit Rev Plant Sci 22, 341-366.

Ormeño, E., Bousquet-Melou, A., Mévy, J.-P., Greff, S., Robles, C., Bonin, G., Fernandez, C., 2007a. Effect of intraspecific competition and substrate nature on terpene emissions of some Mediterranean species. J Chem Ecol 33, 277-286.

Ormeño, E., Fernandez, C., Mevy, J.-P., 2007b. Plant coexistence alters terpene emission and content of Mediterranean species. Phytochemistry 68, 840-852.

Pasqua, G., Monacelli, B., Manfredini, C., Loreto, F., Perez, G., 2002. The role of isoprenoid accumulation and oxidation in sealing wounded needles of Mediterranean pines. Plant Sci 163, 239-248.

Quézel, P. 2000. Taxonomy and biogeography of Meditteranean Pines (Pinus halepensis and P. brutia). In: Ne'eman, G., Trabaud, L., (eds), Ecology, Biogeography and Management of Pinus halepensis and P. Brutia Forest Ecosystems in the Mediterranean Basin. Backhuys. pp 1-12.

Reigosa, M.J., Sánchez-Moreiras, A.M., González, L., 1999. Ecophysiological approach in allelopathy. Crit Rev Plant Sci 18, $577-608$.

Reigosa, M.J., Pedrol, N., Sánchez-Moreiras, A.M., González, L., 2002. Stress and Allelopathy. In: Reigosa, M.J., Pedrol, N. (Eds.), Allelopathy: From Molecules to Ecosystems. Science Publlishers Inc., Plymouth, pp. 231-256.

Rice, E.L., 1984. Allelopathy. Academic Press, New York.

Robles, C., Greff, S., Pasqualini, V., Garzino, S., Bousquet-Melou, A., Fernandez, C., Korboulewsky, N., Bonin, G., 2003. Phenols and flavonoids in Pinus halepensis Mill. needles as bioindicators of air pollution. J Environ Qual 32, 2265-2271.

Stamp, N., Bradfield, M., Li, S., Alexander, B., 2004. Effect of competition on plant allometry and defense. Am Midland Naturalist 151, 50-64.

Zar, J.H., 1984. Biostatistical Analysis, 2ème ed. Prentice Hall International, U.K. 